\title{
Modeled microgravity inhibits apoptosis in peripheral blood
}

\section{lymphocytes*}

\author{
${ }^{1}$ Diana Risin and ${ }^{2}$ Neal R. Pellis
}

1Wyle Laboratories - Life Sciences, Systems and Services, 1290 Hercules Drive, a

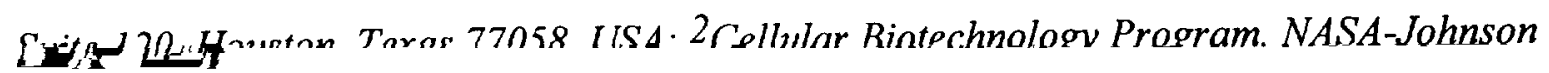

Space Center, 2101 NASA Road 1, Mail Code:SD12, Houston, Texas 77058, USA.

$1_{e-m a i l: d r i s i n @ e m s . j s c . n a s a . g o v}$

Our previous observations that microgravity interferes with numerous lymphocyte functions (expression of cell surface molecules, locomotion, polyclonal and antigen-specific activation, protein kinase $C$ activity) indirectly indicated that it might also affect programmed cell death (PCD) in lymphocyte populations. To test this assumption, we examined spontaneous, activation- and radiation-induced PCD in peripheral blood mononuclear cells (PBMC) exposed to modeled microgravity. The results establish a novel biological phenomenon inhibition of apoptosis in modeled microgravity and provide insights in the mechanisms of this phenomenon.

* Presented in part at the European Low Gravity Research Association Meeting and General Assembly (Rome, Italy, 2/28 - 3/3/99). 


\section{INTRODUCTION}

Impairment of the immunity in astronauts and cosmonauts even in short term flights is a recognized risk ${ }^{1}$. Long term orbital space missions and anticipated interplanetary flights increase the concern for more pronounced effects on the immune system with potential clinical consequences. Impairment of the immunity in space may be due to numerous physiological changes caused by space-related factors, which in turn affect the immune system, or alternatively, it may be due to direct effects of different factors ençountered in space on lymphoid cells and their interactions.

Indeed, in modeled microgravity (MMG) experiments on Earth we and others ${ }^{2-9}$ showed that microgravity directly affects multiple lymphocyte functions. It interferes with expression of cell surface molecules ${ }^{8}$, causes inhibition of lymphocyte locomotion $^{6}$, suppresses polycloṇal and antigen-specific lymphocyte activation ${ }^{2-5,7,8}$, selectively inhibits protein kinase $\mathrm{C}$ (PKC) isoforms ${ }^{7}$. Some of these effects were also confirmed in cell culture experiments in real space conditions $^{6,10-13}$ during Spacelab, Biokosmos and Shuttle Missions. The results of these studies, taken together, strongly indicated that microgravity interferes with fundamental biological processes associated with functional and structural changes in cell surface membranes, cell surface molecules and in their interaction. Based on the data and on their interpretation, we hypothesized that microgravity in addition to observed functional changes affects programmed cell death (PCD) in lymphocyte populations and that this mechanism could contribute to the impairment of the immunity. This is supported by the following considerations. First, the immune response critically depends on permanent cell renewal and differentiation. Second, apoptosis plays a pivotal role in the process of cell renewal and in sustaining tissue homeostasis, 
especially in such dynamic cell populations as the immune system. Third, apoptosis is known to be regulated through the surface-related interactions, which might be gravity-dependent.

The objective of this study was to test the hypothesis whether modeled microgravity affects programmed cell death in lymphocyte cell populations and through this mechanism interferes with the immune functions.

Studies on apoptosis in lymphoid cells in microgravity are limited to a few observations ${ }^{14,15}$. However, it is difficult to relate the results of this studies to the analysis of the impairment of the immune response in space since they were performed either on immortalized permanently proliferating cells (Jurkat) or on lymphoid cells isolated from lymphoid organs of experimental animals flown in space. Our experiments were conducted on human PBMC and activated T cells and microgravity was modeled using rotating wall vessel culture system that providẹs three essential conditions: 1) randomization of the gravity vector through the cell, 2) a state of continuous fall, and 3) maintaining a quiescent, low shear environment ${ }^{16-19}$.

\section{Results}

\section{Spontaneous and radiation induced PCD in MMG and stationary conditions.}

The level of spontaneous apoptosis in stationary conditions in non-activated PBMC as well as in activated $\mathrm{T}$ cells was under $6 \%$. It was practically the same in cultures from RWV (Table 1). Radiation caused a substantial increase in PCD (Fig. 1). Consistent with other investigations ${ }^{20.21}$, we have found that the effect of radiation on PCD is dose dependent. The highest level of apoptotic death in stationary culture conditions was observed at $20 \mathrm{~Gy}$ (Fig.1). We have also 
observed that the sensitivity of PBMC to radiation-induced PCD varied among the individual donors.

Maintaining the PBMC after radiation in rotating wall vessel caused substantial reduction in the number of cells undergoing programmed cell death (Fig. 1). The inhibitory effect was most prominent in those cell samples that demonstrated the highest levels of radiation-induced PCD in stationary conditions.

\section{Activation-induced PCD in MMG.}

To examine whether microgravity interferes with mechanisms involved in triggering of apoptosis in PBL during immune response, we analyzed the effect of modeled microgravity on activationinduced PCD. For this purpose, we used isolated T cells, activated by Anti-CD3 antiboğlies and IL-2 and restimulated by exposure to PHA-M or to PMA+ionomycin as described below. Reengagement of T cell receptor in this model by PHA induced PCD in the range of $42.9 \%$ to $64.7 \%(49.2 \pm 1.51 \%)$. The level of PCD trigged by adding PMA and ionomycin was in the range of $23.5 \%$ to $42.3 \%$ (32.5 $\pm 2.31 \%$ ). Again, exposure to modeled MG significantly reduced $\mathrm{PCD}$ (Fig. 2).

Apoptotic death of the cells was confirmed by transmission electron microscopy, which revealed characteristic cytoplasmic and nuclear changes (data not shown).

\section{Receptor-ligand interaction in MMG.}

To approach the possible mechanisms of the observed rescue effect of MMG, we investigated the conceivable impact of microgravity on receptor-ligand interaction (T cell receptor - PHA). For 
this purpose, we examined the possibility to abrogate the MG-induced inhibition of apoptosis by stimulation of the activated T cells with PHA in stationary conditions prior to their transfer to the RWV. Regardless of the sequence of the events - whether PHA was added prior or during exposure to microgravity - no substantial difference in the extent of apoptosis was observed (Fig. 3). These results strongly suggest that the interaction between PHA and cell surface receptor molecules remains intact in modeled $M G$ and does not contribute to the observed inhibitory effect. This conclusion was also supported by direct measurements of binding of FITC-labeled PHA to lymphocytes in stationary and microgravity conditions, which showed that the level of binding was practically the same in stationary and MMG conditions ${ }^{8}$.

\section{The effect of MG on Fas and Fas ligand expression and interaction.}

Another possibility examined in this study is the interference of modeled MG with Fas and FasL expression and interaction. No difference in expression of membrane-bound Fas Ag (Fig. 4) and Fas ligand in simulated MG vs stationary conditions in either activated or activated and restimulated by PHA T cells was observed. The level of Fas ligand expression on the surface of these cells both in MG and stationary conditions was very low, almost marginal.

At the same time, adding of exogenous recombinant soluble Fas ligand into the media before cell placement in MG totally abrogated the inhibitory effects (Fig. 5).

\section{The effect of MG on the expression of Bcl-2 family proteins.}

No difference was found in the expression of Bcl-2 protein or bax antigen between the activated $\mathrm{T}$ cells maintained either in stationary or in RWV conditions. This was also confirmed in 
experiments in which PCD in preliminary activated T cells was triggered by PHA (Figs. 6 and 7).

\section{DISCUSSION}

The results demonstrate that modeled microgravity inhibits PCD in lymphocyte populations. Inhibition occurred in two types of experiments: 1) when PCD was induced by gamma-radiation of PBMC, and 2) when PCD in activated T cells was triggered by PHA-M or PMA+ionomycin restimulation. The results obtained in both systems demonstrate a significant decrease in apoptosis when human lymphocytes are transitioned to modeled microgravity. The model, in which PCD is induced in activated $\mathrm{T}$ cells through the mechanism of reengagement of $\mathrm{T}$ cell receptor, is particularly important. It represents in vitro the main mechanism involved in triggering apoptotic death in lymphocytes during physiological immune response and thus, relates the findings to the immune response in vivo.

The observed rescue effect indicates that $\mathrm{MG}$ might interfere with the major physiological mechanisms involved in control of PCD in lymphoid cells. To elucidate the possible MGsensitive mechanisms of apoptosis several assumptions were investigated. First, whether microgravity interferes with receptor-ligand interaction, in our case - PHA and PHA-receptor. Thus we attempted to abrogate the effects of $M G$ by engagement of the PHA receptors by the ligand molecules in stationary conditions prior to placing the cells in the RWV. There was no substantial difference in the extent of apoptosis regardless of whether PHA was added prior or during exposure to microgravity (Fig. 3), suggesting that the interaction between PHA and cell surface receptor molecules remained intact in modeled MG. 
The second possibility is the interference of MG with the expression and with the interaction of Fas and Fas ligand, which play a key role in triggering activation-induced apoptosis, including PCD triggered by PHA and PMA+ionomycin ${ }^{22}$. This mechanism is documented in nontransformed $\mathrm{T}$ cells, $\mathrm{T}$ cell hybridomas, and in alloreactive $\mathrm{T}$ cell clones ${ }^{23-28}$. $\mathrm{T}$ cell receptor triggering upregulates Fas and induces expression of the Fas ligand an cell surface. Further interaction of Fas and Fas ligand on the surface of the same or neighboring cells initiates the necessary steps for the suicide program. Fas-FasL interactions are also inyolved in PCD induced by ionizing radiation in malignant and normal lymphocytes ${ }^{29}$. Based on these and other data it was anticipated that this mechanism may be affected by MMG. However, we did not find any difference in the expression of Fas antigen and membrane-bound FasL on the surface of activated $\mathrm{T}$ cells cultured either in stationary or in modeled microgravity conditions. The expression of Fas ligand on the surface of cultured cells was found to be marginal, which is consistent with other observations on the level of FasL expression ${ }^{26}$. These results may indicate that the role of Fas-FasL mechanism in modeled microgravity-induced inhibition of apoptosis is minimal, if any. At the same time, the inhibition of apoptosis in MG was totally abrogated by exogenous soluble Fas ligand. This suggests that microgravity most likely affects not the expression, but the interaction of membrane-bound Fas $\mathrm{Ag}$ and Fas ligand on the surface of the same or neighboring cells. When soluble FasL becomes available in the media the apoptotic program is fully activated. However, shedding of the membrane bound FasL into the media is extremely low and not sufficient to trigger the process and to overcome the inhibitory effects of MG.

The third assumption is the involvement of the $\mathrm{Bcl}-2$ family proteins. Members of the $\mathrm{Bcl}-2$ family regulate apoptosis in mammals and may act as inhibitors or promoters of apoptosis. The most prominent regulators are $\mathrm{Bcl}-2, \mathrm{Bcl}-\mathrm{x}_{\mathrm{L}}$ and $\mathrm{Bax}^{30-33}$. The $\mathrm{Bcl}-2$ family members dimerize, 
with one monomer antagonizing or enhancing the function of the other. For example proapoptotic proteins such as Bax dimerize with anti-apoptotic family member $\mathrm{Bcl}-2^{34-36}$. In this way, the ratio of inhibitors to activators in a cell determines the outcome, namely, whether the cell will undergo apoptosis, or this process will be abolished ${ }^{37,38}$. This issue lately became more uncertain, when it was demonstrated that heterodimerization is not required for pro-survival activity $^{39}$. It was also shown that certain death signals, including CD95-mediated apoptosis in peripheral $\mathrm{T}$ cells, could bypass control by $\mathrm{Bcl}-2^{40}$. We did not find, any difference in the expression of $\mathrm{Bcl}-2$ protein or bax antigen in cells maintained in stationary conditions and in RWV with or without PHA triggering (Fig. 5 and 6). This indicates that inhibition of apoptosis in activated $\mathrm{T}$ lymphocytes in modeled $\mathrm{MG}$ may not be related to changes in expression of bcl-2 or bax antigen.

In summary, our findings demonstrate for the first time in the literature a new biological phenomenon - inhibition of apoptotic cell death in modeled microgravity conditions. The exact mechanism/s of this phenomenon is/are unknown. However, it is unlikely that changes in the expression of Fas antigen, Fas ligand, bcl-2 or bax protein are involved. The fact that inhibition of apoptosis is abrogated by exogenous soluble FasL implies that the MMG impairs membranebound Fas and FasL interaction. MMG may inhibit apoptosis by 1) altering receptor affinity for the ligand, 2) interfering with receptor distribution, or 3) minimizing the tangential area of cellcell interaction and thereby preventing the threshold interaction level necessary for signal transduction.

In general we consider that $\mathrm{MG}$ interferes with certain, yet unknown conditions important for molecular interaction involved in PCD. It may be changes in the cell shape, in the cytoskeleton, in cell movement, or in any other vector-dependent molecular rearrangements. 


\section{METHODS}

Peripheral blood mononuclear cells (PBMC) were isolated from healthy donors using

a Ficoll Hypaque gradient (Ficoll-Paque, Pharmacia Biotech AB, Uppsala, Sweden) by centrifugation at $700 \mathrm{~g}$ for $20 \mathrm{~min}$ at room temperature. The cells from the interface were washed three times with Hanks balanced salt solution (HBSS) and resuspended in RPMI-1640 medium supplemented with $10 \%$ fetal bovine serum (FBS).

Activation of $T$ cells was achieved by PBMC stimulation by anti-CD3 antibodies (generous gift of Dr. Bradley W. McIntyre, University of Texas M. D. Anderson Cancer Center) at a final concentration $100 \mathrm{ng} / \mathrm{ml}$ and human recombinant IL-2 $(100 \mathrm{U} / \mathrm{ml}$, Life Technologies, Grand Island, NY) for 3-4 days. The cells were replenished with IL-2 (100 U/ml) every 3-4 days. They were used in the study following at least 11 days of activation.

Induction of apoptosis. Effects of microgravity were investigated in spontaneous and induced apoptosis models. Apoptosis was induced either by gamma irradiation of PBMC or by $\mathrm{T}$ cell receptor reengagement in activated $\mathrm{T}$ cells (so called activation-induced $\mathrm{PCD}$ ).

PBMC were $\gamma$-irradiated using ${ }^{137} \mathrm{Cs}$ source at a dose rate of $15 \mathrm{~Gy} / \mathrm{min}$ in irradiator with a rotating platform. To induce PCD in T lymphocytes previously activated cells were restimulated by PHA-M (final concentration $5 \mu \mathrm{g} / \mathrm{ml}$ ) or by PMA+ionomycin (final concentrations $5 \mathrm{ng} / \mathrm{ml}$ and $500 \mathrm{ng} / \mathrm{ml}$, respectively). All reagents are from Sigma Chemical Co., St. Louis, MO.

In several experiments to induce apoptosis in activated $\mathrm{T}$ cells we used recombinant human soluble Fas ligand (rhs APO-1/Fas ligand, Alexis Biochemicals, San Diego, CA) at $50-80 \mathrm{ng} / \mathrm{ml}$ with $1 \mu \mathrm{g} / \mathrm{ml}$ of an enhancer protein. 
Modeled microgravity and control cell cultures. To approximate MG conditions on Earth we used specialized rotating-wall vessel culture system developed at the NASA-Johnson Space Center and commercially available from Synthecon, Inc. (Friendswood, TX). This very low shear culture system randomizes gravitational vectors and approximates the microgravity environment by sustaining cells in continues free fall ${ }^{16-19}$. This culture system was successfully used before for the analysis of the effects of microgravity on PBMC, locomotion in parallel studies on Earth and in Space performed during space flight missions STS-54 and STS-56 ${ }^{6}$.

Contmalc mare onltured in stationary conditions in nlastic tissue culture flasks. All cultures 
100 (Sigma Chemical Co., St. Louis, MO), and placed at $4^{\circ} \mathrm{C}$ in the dark until the flow cytometric analysis. The PI fluorescence of the nuclei was measured using a Coulter EPICS flow cytometer (Hialeah, FL). The percentage of apoptotic nuclei was estimated by assessment of the hypodiploid DNA peak in the DNA fluorescence histogram.

Cell surface Fas/CD95 and Fas ligand/CD95L expression was examined by flow cytometry (EPICS C; Coulter, Hialeah, FL). Staining for CD95 was accomplished by incubating of $1 \times 10^{6}$ cells with saturating concentration of anti-human Fas $\mathrm{mAb}$, (clone $7 \mathrm{C} 11$, Coulter Corporation, Miami, FL) directly conjugated with RD1-phycoerythrin derivative for 40 min. RD1-conjugated mouse IgM Ab were used as a control. Stained cells were washed twice in cold HBSS with $2 \%$ FBS. All incubations were carried out at $4^{0} \mathrm{C}$. Staining for Fas ligand (FasL) was performed using biotin conjugated mouse anti-human Fas ligand monoclonal antibody, clone NOK-1 followed by streptavidin-phycoerythrin conjugate. Biotin-conjugated mouse $\mathrm{IgG}_{1}, \mathrm{~K} \mathrm{Ab}$ were used as a control. All reagents from PharMingen, San Diego, CA. Cell surface Fas ligand expression was also analyzed using directly FITC-conjugated monoclonal rat antihuman Fas ligand Ab (clone H11, Alexis Biochemicals, San Diego, CA). Percentage of positive cells and mean channel fluorescence were calculated by subtracting the control histogram from the test histogram using a cumulative subtraction routine (Oversub) within the Elite Immuno-4 software (Coulter Corp., Healeah, FL).

$\mathrm{Bcl}-2$ and Bax protein expression. For immunodetection of the intracellular bcl-2 protein we used FITC-conjugated monoclonal mouse $\mathrm{Ab}$ against human bcl-2 oncoprotein (Accurate Chemical \& Scientific Corporation, Westbury, NY) and followed the manufacture's protocol. Briefly, the cells were washed with PBS, permeabilized and fixed in $0,25 \%$ 
paraformaldehide and $70 \%$ methanol. After that, the monoclonal $\mathrm{Ab}\left(10 \mu \mathrm{l}\right.$ per $1 \cdot 10^{5}$ cells) were added and the cells were incubated for $30 \mathrm{~min}$ at $4^{\circ} \mathrm{C}$. The cells were stained in DNA-staining medium which contained $50 \mu \mathrm{g} / \mathrm{ml} \mathrm{PI}$ and $100 \mathrm{units} / \mathrm{ml}$ ribonuclease A. Mouse FITC-conjugated IgG1 Ab were used as a negative control.

For immunodetection of bax protein monoclonal mouse Ab against human bax (Immunotech, a Coulter Co., Miami, FL) were used. Following cell permeabilization procedure, performed by using IntraPrep ${ }^{\mathrm{TM}}$ Permeabilization Reagent (Immunotech, a Coulter Co., Miami, FL) according the manufacture's protocol, the cells were stained by the unconjugated monoclonal mouse $\mathrm{Ab}$ against human Bax (Immunotech, a Coulter Co., Miami, FL), $2 \mu \mathrm{g}$ per $5 \cdot 10^{5}$ cells for $15 \mathrm{~min}$ at room temperature. After washing in PBS, they were additionally incubated for $15 \mathrm{~min}$ with FITC-conjugated gout anti-mouse secondary antibody (Becton Dickinson, San Jose, $\overline{\mathrm{C} A}$ ) and further analyzed by flow cytometry (EPICS C; Coulter Corp., Healeah, FL). Controls for indirect staining included incubation with FITC-conjugated secondary antibody alone. 
3. Cogoli, A., Bechler, B. and Lorenzi, G. Response of cells to microgravity. In: Fundamentals of Space Biology (M.Asashima and G.M. Malacinski, eds.), Japan Sci. Soc. Press, Tokyo /Springer-Verlag, pp.97-111 (1990).

4. Cogoli, A. The effect of hypogravity and hypergravity on cells of the immune system. $J$. Leuk. Biol., 54, 259-268 (1993).

5. Risin, D., Prewett, T.L. and Pellis, N.R. Suppression of lymphocyte function in microgravity and potential impact on immunosurveillance. Anticancer Res. 15, Number 5A, p. 1652, \#72 (1995).

6. Pellis, N.R., Goodwin, T.J., Risin, D., McIntyre, B. W., Pizzini, R. P., Cooper, D., Baker, T.L. and Spaulding, G.F. Changes in gravity inhibit lymphocyte locomotion through type 1 collagen. In Vitro Cell. Dev. Biol. - Animal 33, 398-405 (1997).

7. Pellis, N. R, Risin, D., Sundaresan, A. and Cooper, D. Direct effect of microgravity (MG) on human lymphocytes: Functional and Morphological aspects. ELGRA News, Bulletin of the European Low Gravity Research Association, 21, 71 (1999).

8. Cooper, D. and Pellis, N.R. Suppressed PHA activation of T lymphocytes in simulated microgravity is restored by direct activation of protein kinase C. J. Leuk. Biol. 63, 550$562(1998)$.

9. Walther, I., Pippia, P., Meloni, M.A., Turrini, F., Mannu, F. and Cogoli, A. Simulated microgravity inhibits the genetic expression of interleukin-2 and its receptor in mitogenactivated T lymphocytes. FEBS Lett 436, 115-118 (1998).

10. Cogoli, A., Tschopp, A. and Fuchs-Bislin, P. Cell sensitivity to gravity. Science, 225, 228230 (1984). 
11. Cogoli, A. and Tschopp, A. Lymphocyte reactivity during spaceflight. Immunology Today, $6,1-4(1985)$

12. Cogoli, A., Bechler, B., Muller, O. and Hunzinger, E. Effect of microgravity on lymphocyte activation. In: Biorack on Spacelab D1. ESA SP-1091 (N. Longdon and V. David, eds.), ESA Publications Division, ESTEC, Noordwijk, The Netherlands p.89-100 (1988).

13. Cogoli, A., Bechler, B., Cogoli-Greuter, M., Criswell, S.B., ,Joller, H., Joller, P., Hunzinger, E. and Muller, O. Mitogenic signal transduction in T lymphocytes in microgravity. J. Leuk. Biol., 53, 569-575 (1993).

14. Congdon, C.C., Allebban, Z., Gibson, L.A., Kaplansky, A., Strickland, K.M., Jago, T.L., Johnson, D.L., Lange, R.D. and Ichiki, A.T. Lymphatic tissue changes in rats flown on Spacelab Life Sciences-2. J. Appl. Physiol., 81, 172- 177 (1996).

15. Lewis, M.L., Reynolds, J.L., Cubano, L.A., Hatton, J.P., Lawless, B.D. and Piepmeier, E.H. Spaceflight alters microtubules and increases apoptosis in human lymphocytes (Jurkat). FASEB J., 12, 1007- 1018 (1998).

16. Schwarz, R. P., Goodwin, T. J. and Wolf, D. A. Cell culture for three-dimensional modeling in rotating-wall vessels: an application in simulated microgravity. J. Tiss. Cult. Meth., 14, 51-58 (1992).

17. Tsao, Y. D., Goodwin, T. J., Wolf, D.A. and Spaulding, G.F. Responses of gravity level variations on the NASA/JSC bioreactor system. The Physiologist, 35, S49-50 (1992).

18. Goodwin, T. J., Prewett, T.L., Wolf, D.A. and Spaulding, G.F. Reduced shear stress: a major component in the ability of mammalian tissues to form three-dimensional assemblies in simulated microgravity. J. Cell. Biochem. 51, 301-311 (1993). 
19. Jessup, J. M., Goodwin, T. J. and Spaulding, G.F. Prospects for use of microgravitybased bioreactors to study three-dimensional host-tumor interactions in human neoplasia. J. Cell. Biochem. 51, 290-300 (1993).

20. Delic, J., Morange, M. and Magdelenat, H. Ubiquitin pathway involvement in human lymphocyte $\gamma$-irradiation-induced apoptosis. Mol.Cell. Biol. 13, 4875-4883 (1993).

21. Seki, H., Kanegane, H., Iwai,K., Konno, A., Ohta, K., Yachie, A., Taniguchi, N. and

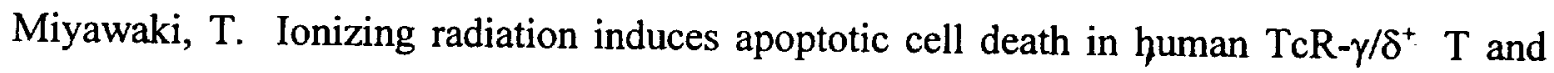
natural killer cells without detectable p53 protein. Eur. J. Immunol. 24, 2914-2917 (1994).

22. Brunner, T., Yoo, N.J., Griffith, T.S., Ferguson, T.A. and Green, D.R. Regulation of CD95 ligand expression: a key element in immune regulation. Behring Inst. Mitt. 97, 161-174 (1996).

23. Singer, G.G. and Abbas, A.K. The Fas antigen is involved in peripheral but not thymic deletion of T lymphocytes in T cell receptor transgenic mice. Immunity, 1,365-371 (1994).

24. Alderson, M. R., Tough, T.W., Davis-Smith, T., Braddy, S., Falk, B., Schooley, K.A., Goodwin, R.G., Smith, C.A., Ramsdell, F. and Lynch, D.H. Fas ligand mediates activation-induced cell death in human T lymphocytes. J.Exp.Med., 181, 71-77 (1995).

25. Brunner, T., Mogil, R.J., LaFace, D., Yoo, N.J., Mahboubi, A., Echeverri, F., Martin, S.J., Force, W.R., Lynch, D.H., Ware, C.F. and Green, D.R. Cell-autonomous Fas (CD95)/Fas-ligand interaction mediates activation-induced apoptosis in T-cell hybridomas. Nature, 373, 441-444 (1995).

26. Dhein, J., Walczak, H., Baumler, C., Debatin, K-M. and Krammer, P.H. Autocrine T-cell suicide mediated by APO-1/(Fas/CD95). Nature, 373, 438-441 (1995). 
27. Ju, S-T., Panka, D.J., Cui, H., Ettinger, R., El-Khatib, M., Sherr, D.H., Stanger, B.Z. and Marshak-Rothstein, A. Fas (CD95)/FasL interections required for programmed cell death after T-cell activation. Nature, 373, 444-448 (1995).

28. Van Parijs, L., Ibraghimov, A., and Abbas, A. K. The roles of costimulation and Fas in T cell apoptosis and peripheral tolerance. Immunity, 4, 321-328 (1996).

29. Belka, C., Marini, P., Budach, W., Schulze-Osthoff, K., Lang, F., Gulbins, E. and Bamberg, M. Radiation-induced apoptosis in human lymphocytes and lymphoma cells critically relies on the up-regulation of CD95/Fas/APO-1 ligand. Radiat.Res., 149, 588-595 (1998).

30. Reed, J.C. Bcl-2 and the regulation of programmed cell death. J. Cell. Biol., 124, 1-6 (1994).

31. Chao, D.T. and Korsmeyer, S.J. BCL-2 family: regulators of cell death. Ann. Rev. Immunol., 16, 395-419 (1998).

32. Reed, J.C. Bcl-2 family proteins. Oncogene 17, 3225-3236 (1998).

33. Zamzami, N., Brenner, C., Marzo, I., Susin, S.A. and Kroemer, G. Subcellular and submitochondrial mode of action of Bcl-2-like oncoproteins. Oncogene, 16, 2265-2282 (1998).

34. Oltvai, Z.N., Milliman, C.L. and Korsmeyer, S.J. Bcl-2 heterodimerizes in vivo with a conserved homolog, Bax, that accelerates programmed cell death. Cell, 74, 609-619 (1993).

35. Yin, X.M., Oltvai, Z.N. and Korsmeyer, S.J. BH1 and BH2 domains of Bcl-2 are required for inhibition of apoptosis and heterodimerization with Bax. Nature, 369, 321-323 (1994). 
36. Sedlak, T.W., Oltvai, Z.N., Yang, E., Wang, K., Boise, L.H., Thompson, C.B. and Korsmeyer, S.J. Multiple Bcl-2 family members demonstrate selective dimerization with Bax. Proc.Natl.Acad. Sci.USA 92, 7834-7838 (1995).

37. Korsmeyer, S.J., Shutter, J.R., Veis, D.J., Merry, D.E. and Oltvai, Z.N. Bcl-2/Bax: a rheostat that regulates an anti-oxidant pathway and cell death. -Semin. Cancer Biol., 4, 327-332 (1993).

38. Oltvai,, Z.N. and Korsmeyer, S.J. Checkpoints of dueling dimers foil death wishes. Cell, 79,189-192 (1994).

39. Cheng, E.H., Levine, B., Boise, L.H., Thompson, C.B. and Hardwick, J.M. Baxindependent inhibition of apoptosis by Bcl-XL. Nature, 379, 554-556 (1996).

40. Krammer, P. H. CD95(APO-1/Fas)-Mediated Apoptosis: Live and Let Die. - Adv. in Immunol., 71, 163-210 (1999).

41. Muller, H.K, Bucana, C.D., Kripke, M.L., Cox, P.A., Saijo, S. and Strickland, F. M. Ultraviolet irradiation of murine skin alters cluster formation between lymph node dendritic cells and specific T lymphocytes. Cell. Immunol., 157, 263-276 (1994).

42. Nicoletti, I., Migliorati, G., Pagliacci, M.C., Grignani, F. and Riccardi, C. A rapid and simple method for measuring thymocyte apoptosis by propidium iodide staining and flow cytometry. J. Immunol. Methods, 139, 271-279 (1991). 


\section{Figure Legends}

Figure 1 Spontaneous and radiation-induced PCD in human PBMC maintained in stationary and microgravity conditions. PBMC were $\gamma$-irradiated at $7.5 ; 20$ and 40 Gy and then cultured in RWV or in stationary conditions. PCD was assessed 18 hrs after restimulation. Data are presented as mean \pm standard error of the mean.

Figure 2 Effect of modeled microgravity on spontaneous, PHA, and PMA+ionomycin induced programmed cell death in activated peripheral blood $\mathrm{T}$ cells. Activated $\mathrm{T}$ cells were restimulated by PHA-M or by PMA+ionomycin and then cultured in RWV or stationary conditions. PCD was assessed $18 \mathrm{hrs}$ after restimulation. Data are presented as mean $\pm \bar{s}$ standard error of the mean.

Figure 3 PHA-induced PCD in activated $T$ cells exposed to microgravity at different time points. PHA was added to activated T cells $2 \mathrm{hrs}$ prior ( -2 time point), immediately before (0 time point) or 24 hrs after (24 time point) cell placement into RWV. PCD was assessed 18 hrs after restimulation and compared with PCD in cells restimulated and kept for the same time in stationary conditions. Data are presented as mean \pm standard error of the mean. 
Figure 4 Fas antigen expression in activated $T$ cells restimulated with PHA. Activated $T$ cells were cultured in RWV or in stationary conditions. The cells were sampled after 24 hrs in culture without restimulation and 2, 6 or 18 hrs after restimulation by PHA. Fas antigen expression was assessed at all time points and the data are presented as mean \pm standard error of the mean.

Figure 5 Effect of modeled microgravity on FasL induced programmed cell death in activated peripheral blood $T$ cells. Soluble FasL was added to activated $\mathrm{T}$ cells cultured in RWV or in stationary conditions and PCD was assessed $18 \mathrm{hrs}$ after. Data are presented as mean \pm standard error of the mean

Figure 6 Bcl-2 expression in activated T cells restimulated with PHA. Activated T cells were cultured in RWV or in stationary conditions. The cells were sampled after $24 \mathrm{hrs}$ in culture without restimulation and 2, 6 or $18 \mathrm{hrs}$ after restimulation by $\mathrm{PHA}$. Bcl-2 expression was assessed at all time points and the data are presented as mean \pm standard error of the mean.

Figure 7 Bax expression in activated $T$ cells. Activated T cells were cultured in RWV or in stationary conditions. The cells were sampled after $24 \mathrm{hrs}$ in culture. Bax expression was assessed and the data are presented as mean \pm standard error of the mean. Panel A - Percent positive cells, Panel B - Mean fluorescence intensity. 


\section{Table 1. Spontaneous apoptosis in PBMC and Activated T cells in stationary and modeled MG conditions}

\author{
Static
}

PBMC

Act. T-cells

$$
\begin{gathered}
5.95 \pm 1.01 \\
(\mathrm{n}=4)
\end{gathered}
$$$$
5.32 \pm 0.40
$$$$
(\mathrm{n}=12)
$$

RWY P

$$
\begin{aligned}
& 5.1 \pm 0.98 \\
& (n=4)
\end{aligned}>0.05
$$

$6.79 \pm 0.67>0.05$

$(n=12)$

Human PBMC and activated T cells were cultured in RWV or in stationary conditions for 18-24 hrs. Cells were harvested and apoptosis assessed by Flow cytometry. Data are presented as mean \pm standard error of the mean. 